\title{
Hybrid materials utilizing polyelectrolyte-derivatized carbon nanotubes and vanadium-mixed addenda heteropolytungstate for efficient electrochemical charging and electrocatalysis
}

\author{
Marta Sosnowska • Monika Goral-Kurbiel • \\ Magdalena Skunik-Nuckowska • Rafal Jurczakowski • \\ Pawel J. Kulesza
}

Received: 25 January 2013 /Revised: 3 April 2013 / Accepted: 6 April 2013 /Published online: 18 April 2013

(C) The Author(s) 2013. This article is published with open access at Springerlink.com

\begin{abstract}
Preparation and electrochemical behavior of new hybrid materials composed of multi-walled carbon nanotubes (CNTs) that were derivatized with poly(diallyldimethylammonium) chloride and modified with vanadium-mixed addenda Dawson-type heteropolytungstate, $\left[\mathrm{P}_{2} \mathrm{~W}_{17} \mathrm{VO}_{62}\right]^{8-}$, is described here. These nanostructured composite systems exhibited fast dynamics of charge propagation. They were characterized by the transport (effectively diffusional) kinetic parameter of approximately $8 \times 10^{-8} \mathrm{~cm}^{-2} \mathrm{~s}^{-1 / 2}$ and the specific capacitance parameter of $82 \mathrm{~F} \mathrm{~g}^{-1}$ (at the charging/discharging current of $200 \mathrm{~mA} \mathrm{~g}^{-1}$ ). The latter parameter for bare CNTs was found to be only $50 \mathrm{~F} \mathrm{~g}^{-1}$ under analogous conditions. These observations were based on the results of galvanostatic charging-discharging, cyclic voltammetric, and AC impedance spectroscopic measurements. The improved capacitance properties were attributed to the systems' pseudocapacitive features originating from the fast redox transitions of the $\left[\mathrm{P}_{2} \mathrm{~W}_{17} \mathrm{VO}_{62}\right]^{8-}$ polyanions. In addition to the fast redox conduction, the proposed organicinorganic hybrid materials exhibited interesting electrocatalytic activity toward reduction of bromate in the broad concentration range (sensitivity, $0.24 \mathrm{~mA} \mathrm{~cm}^{-2} \mathrm{mmol}^{-1} \mathrm{dm}^{3}$ ).
\end{abstract}

Keywords Multi-walled carbon nanotubes · Vanadium mixed addenda heteropolytungstate .

Poly(diallyldimethylammonium) chloride · Faradaic (redox) pseudocapacitance $\cdot$ Bromate reduction

M. Sosnowska • M. Goral-Kurbiel • M. Skunik-Nuckowska R. Jurczakowski $\cdot$ P. J. Kulesza $(\bowtie)$

Department of Chemistry, University of Warsaw, Pasteura 1, 02-093 Warsaw, Poland

e-mail: pkulesza@chem.uw.edu.pl

\section{Introduction}

Polyoxometalates (POMs) are a class of inorganic nanometer size metal-oxide cluster compounds [1]. Their electrochemical properties such as high stability and conductivity, as well as ability to undergo reversible multiple electron transfer redox processes, make them promising materials to construct electrode materials of electrochemical applications in various areas such as electrocatalysis [2], electrochromic and photochromic devices [3, 4], corrosion protection [5], ion-selective membranes [6], or electrochemical capacitors [7]. There are two principal types of polyoxometalates structures, namely Keggin $\left(\left[\mathrm{XM}_{12} \mathrm{O}_{40}\right]^{3-/ 4-}\right.$ ) and Wells-Dawson $\left(\left[\mathrm{X}_{2} \mathrm{M}_{18} \mathrm{O}_{62}\right]^{8-}\right)$ type, where $\mathrm{X}$ is the non-metallic element such as $\mathrm{P}, \mathrm{Si}$, and $\mathrm{As}$ while $\mathrm{M}$ is a metal redox center, usually $\mathrm{W}^{(\mathrm{VI})}, \mathrm{Mo}^{(\mathrm{V})}, \mathrm{V}^{(\mathrm{V})}$, $\mathrm{Nb}^{(\mathrm{V})}$, or $\mathrm{Ta}^{(\mathrm{V})}[1]$. The presence of more than one metallic center was also reported. It has been demonstrated that tungsten or molybdenum can be substituted by vanadium within the polyoxometalates framework [8-13]. Substituted POMs' polyanions are characterized by higher negative charges. Therefore, they tend to exhibit better stability in a wide range of $\mathrm{pHs}$, even up to neutral $\mathrm{pH}$. Consequently, their applications in medicine and many biological systems have been considered [9].

Due to their small size and high charge, POMs are, in general, fairly well soluble in many solvents. Therefore, to use POMs as active electrode materials, a development of their immobilization methods is required. Recently, various hybrid systems with POMs have been proposed and studied for solid-state applications [14-16]. Common representative examples include the systems containing POMs immobilized within conducting polymers [17], gel matrices [18], 
Langmuir-Blodgett layers [19], or as adsorbates existing on nanoparticles' surfaces [20-22]. A high anionic charge of POM layers or adsorbates permits their application as linking agents during fabrication of three-dimensional network films consisted of anionic and cationic species interconnected via simple electrostatic interactions. This layer-by-layer concept was applied to the formation of POM-based hybrid films containing conducting polymers [20-23], positively charged organics like poly(vinylpyridine) or poly(ethylenimine) [24] and transition metal (Fe, $\mathrm{Ru}, \mathrm{Os}, \mathrm{Cu})$ complexes [2, 25-27].

It should be also mentioned that POMs are characterized by the ability to undergo strong spontaneous adsorption on such electrode substrates (or nanosized particles) as carbon, platinum, or gold [20-22]. The efficiency of adsorption strongly depends on the POMs composition and the choice of an electrode material [28]. Therefore, a reasonable approach allowing a stable attachment of almost any POM involves the electrode surface pretreatment leading to the formation of positively charged monolayer capable of electrostatic interaction with reversed charged POM-based film generated in the next step. For this purpose, some organic reactants such as cysteamine, 4-aminothiophenole, and 1,12-diaminododecane were previously applied [29-31]. Recently various organic polyelectrolytes (with charged functional groups) including poly(diallyldimethylammonium) chloride (PDDA) were utilized to fabricate novel multilayered materials [32].

In the present work, the preparation of the hybrid material composed of PDDA-derivatized CNTs and an unique (namely containing two distinct, tungsten, and vanadium, redox centers as well as being highly negatively charged) polyanion, $\left[\mathrm{P}_{2} \mathrm{~W}_{17} \mathrm{VO}_{62}\right]^{8-}$, is described. It is noteworthy that up to now a large portion (ca. $80 \%$ ) of POM applications concentrated on their electrocatalytic features, particularly with respect to induced electroactivity of such inert inorganic reactants $[9,26,33-37]$ as bromate, chlorate, nitrite, hydrogen peroxide (reductions) or ascorbic acid, $\mathrm{NADH}$, and L-cysteine (oxidations). POMs were also reported to have a beneficial effect on oxygen reduction process [28]. With regard to electrochemical charging in redox supercapacitors, POMs were not commonly used regardless a few recent reports which indicated a large contribution of charge exchanged during multiple redox processes of POMs to overall capacitance $[7,14,15$, 38-40]. Composite materials, which are composed of conducting polymers and POMs $[14,15]$, POMs with CNTs, or activated carbons [7, 38], have been already described. Depending on the charge storage mechanism, electrochemical capacitors (often termed as supercapacitors) could be classified into two types [41]: electrical double-layer capacitors (EDLCs) and so-called faradaic (redox-type) capacitors. The EDLC capacitance arises from the charge separation at the porous carbon electrode-electrolyte interface while the faradaic capacitance (or pseudocapacitance) arises from the fast, reversible redox reactions occurring at the interface or near the solid electrode surface. Among carbon materials, carbon nanotubes (CNTs) have been widely examined as electrode materials for supercapacitors [41-43]. Between their important features, a good mechanical strength, high electric conductivity, and reasonably high specific surface area [41] should be mentioned. The capacitance values characteristic of systems utilizing CNTs have been reported to vary from $4 \mathrm{~F} \mathrm{~g}^{-1}$ [42] to $335 \mathrm{~F} \mathrm{~g}^{-1}$ for chemically activated CNTs [44]. We explore here CNTs mostly because of their ability to act as rigid carriers capable of fast electron distribution, in addition to their inherent capacitive properties.

A layer-by-layer concept to assemble uniformly components on electrode surface in a controlled manner was utilized here to modify CNTs with the vanadium-mixed addenda Dawson-type POM, using PDDA as a cationic "inter-layer." The $\left[\mathrm{P}_{2} \mathrm{~W}_{17} \mathrm{VO}_{62}\right]^{8-}$ polyanions were attached to PDDAderivatized CNTs in order to improve electroactivity and to increase the system's overall capacitance through the pseudocapacitive (redox) effect. The $\left[\mathrm{P}_{2} \mathrm{~W}_{17} \mathrm{VO}_{62}\right]^{8-}$ was chosen as an example of mixed polyoxometalate capable to undergo fast and reversible multiple electron transfers. The reduction of the $\left[\mathrm{P}_{2} \mathrm{~W}_{17} \mathrm{VO}_{62}\right]^{8-}$ anion involves the addition of up to seven electrons. Moreover, this POM was previously found to be stable in both acid and neutral media and to behave well within the multilayer assembly film [45]. The choice of PDDA was suggested by the literature reports [46, 47]. For example, a reasonable strategy of functionalization of PDDA-coated CNTs with Keggin- and Dawson-type POMs has been recently reported [47]. In the present work, the emphasis was put on the charge propagation (chargingdischarging) phenomena and the potential electrocatalytic properties of the unique vanadium-mixed addenda Dawsontype heteropolytungstate, $\left[\mathrm{P}_{2} \mathrm{~W}_{17} \mathrm{VO}_{62}\right]^{8-}$.

\section{Experimental}

\section{Materials}

$\alpha_{1}-\mathrm{K}_{8}\left[\mathrm{P}_{2} \mathrm{~W}_{17} \mathrm{VO}_{62}\right] \cdot 10 \mathrm{H}_{2} \mathrm{O}$ was synthesized and characterized according to the literature [48]. The $\alpha_{1}$-form was suggested as a characteristic fingerprint for the $\alpha_{2}$-form [49] was not observed during voltammetric study. The system's UV-vis spectrum (in aqueous buffer $\mathrm{pH} 4.5$ ) was as follows: band from $200-400 \mathrm{~nm}$ associated with $\mathrm{W} \rightarrow \mathrm{O}$ charge transfer, CT absorption, and bands associated with intervalence CT transition $\mathrm{V}^{\mathrm{IV}} \rightarrow \mathrm{W}^{\mathrm{VI}}: \lambda_{\max }=427 \mathrm{~nm}, \varepsilon_{427}=$ $600 \mathrm{~cm}^{-1} \mathrm{M}^{-1}$ and $\lambda_{\max }=604 \mathrm{~nm}, \varepsilon_{604}=705 \mathrm{~cm}^{-1} \mathrm{M}^{-1}$. Its infrared spectrum (KBr pellet) included $\mathrm{P}-\mathrm{O}$ bands at 1,014 and $1,046 \mathrm{~cm}^{-1}$. Results were in agreement with literature [48]. The other chemicals were commercial materials of 
reagent grade. Multi-walled carbon nanotubes (outer diameter 10-30 nm, inner diameter 3-10 nm, length $1-10 \mu \mathrm{m}$, specific surface area: approximately $\left.240 \mathrm{~m}^{2} \mathrm{~g}^{-1}\right), 35 \mathrm{wt} . \%$ PDDA $\left(M_{\mathrm{W}}<100,000\right)$, and $5 \%$ Nafion $^{\mathrm{TM}}$ solution (in mixture of lower aliphatic alcohols and water) were obtained from Sigma-Aldrich. Gamma alumina powder $0.05 \mu \mathrm{m}$ and alpha alumina powder 0.3 and $1.0 \mu \mathrm{m}$ were received from BUEHLER. Multi-walled carbon nanotubes were purified before use, according to the procedure described elsewhere [33]. All other chemicals (from POCH) were used as received. The aqueous buffer solutions of $\mathrm{pH} 2,4.5$, and 7 were prepared according to the literature [50]. All solutions were prepared using doubly distilled subsequently deionized (Millipore Milli-Q) water.

\section{Apparatus and procedures}

To perform electrochemical experiments, $\mathrm{CHI} 660$ or $\mathrm{CHI}$ $660 \mathrm{C}$ potentiostat was employed. The measurements were carried out using a three-electrode system. A glassy carbon (GC) electrode $(d=3 \mathrm{~mm})$ and GC plate $(1 \times 1 \mathrm{~cm})$ were used as working electrode, a graphite rod as counter electrode, and a saturated calomel electrode (SCE) as reference electrode. To determine specific capacitance, the GC plate was used so that it was more convenient to weight electrode material. To reduce the amount of used materials, the GC electrode was employed to carry out all other electrochemical experiments. Working electrodes were polished successively with $1.0,0.3$, and $0.05 \mu \mathrm{m}$ alumina powders. They were rinsed with ethanol and distilled water after each polishing step. To ensure removal of dissolved oxygen, all solutions were degassed with nitrogen for $10 \mathrm{~min}$ before all electrochemical studies. Experiments were carried out at room temperature $\left(20 \pm 2{ }^{\circ} \mathrm{C}\right)$.

The active layers of CNTs were prepared using previously described procedure [16] with some modifications. First, $5 \mathrm{mg}$ of purified CNTs was mixed with $0.5 \mathrm{ml}$ of ethanol and diethyl ether solution (wt.\% ratio 97:3) and left under magnetic stirring for $1 \mathrm{~h}$. Then, Nafion ${ }^{\mathrm{TM}}$ solution was added and the mixture was stirred for the next hour. The ink suspension contained approximately $80 \mathrm{wt} . \%$ of CNTs and 20 wt. $\%$ of Nafion ${ }^{\mathrm{TM}}$ ionomer. The suspension was subsequently spread onto GC electrode (or plate) with CNT-based electrode material loading of $0.4 \mathrm{mg} \mathrm{cm}^{-2}$. Next, the resulting CNT layer was chemically modified using the procedure [46] involving the layer-by-layer self-assembly method. Deposition involved three steps, namely immersion in the aqueous solution of $5 \mathrm{~mol} \mathrm{dm}{ }^{-3} \mathrm{HNO}_{3}$ (to form negative charges), 4 wt. $\%$ PDDA, and $5 \mathrm{mmol} \mathrm{dm}^{-3}$ $\left[\mathrm{P}_{2} \mathrm{~W}_{17} \mathrm{VO}_{62}\right]^{8-}$ for 2,10 , and $15 \mathrm{~min}$, respectively. The modified electrode was rinsed with distilled water after each coating step to prevent anions/cations from the solution being adsorbed. The formed active electrode layers were named CNTs/PDDA/[ $\left.\mathrm{P}_{2} \mathrm{~W}_{17} \mathrm{VO}_{62}\right]^{8-}$ composite. The morphology of the $\mathrm{CNTs} / \mathrm{PDDA} /\left[\mathrm{P}_{2} \mathrm{~W}_{17} \mathrm{VO}_{62}\right]^{8-}$ composite material was examined using JEM 1200 EX (JEOL) transmission electron microscope (TEM) operating at $80 \mathrm{kV}$.

\section{Results and discussion}

Preparation and microscopic properties of composite films

To obtain the $\left[\mathrm{P}_{2} \mathrm{~W}_{17} \mathrm{VO}_{62}\right]^{8-}$ modified carbon nanotubes, three different methods of preparation were applied. We examined the formation of the heteropolyanion monolayers in the process of its spontaneous adsorption on CNTs (the direct adsorption on glassy carbon substrate is relatively negligible without special electrochemical (anodic) pretreatment of the electrode which was described elsewhere [52]) from (a) water and (b) $0.1 \mathrm{~mol} \mathrm{dm}^{-3} \mathrm{H}_{2} \mathrm{SO}_{4}$ solutions of $5 \times 10^{-3} \mathrm{~mol} \mathrm{dm}^{-3}\left[\mathrm{P}_{2} \mathrm{~W}_{17} \mathrm{VO}_{62}\right]^{8-}$. The surface concentrations, $\Gamma$ 's, estimated from voltammetric charges collected under the first oxidation (least positive) voltammetric peaks of the $\left[\mathrm{P}_{2} \mathrm{~W}_{17} \mathrm{VO}_{62}\right]^{8-}$ (as in Fig. 2 a discussed later) were


highest value of $\Gamma$ equal to $5.8 \times 10^{-9} \mathrm{~mol} \mathrm{~cm}^{-2}$, which presumably referred to largely uniform and complete coverage of the CNTs with the $\left[\mathrm{P}_{2} \mathrm{~W}_{17} \mathrm{VO}_{62}\right]^{8-}$, was obtained when CNTs (deposited on glassy carbon) were first covered with the cationic PDDA layer as a template for a subsequent attraction of the heteropolyanion. The latter phenomenon can be explained in terms of strong electrostatic interactions between negatively charged POMs and positively charged PDDA [32].

Figure 1 illustrates representative TEM images recorded for CNTs (a) before and (b) after modification of their surfaces with PDDA monolayer, as well as (c) for CNTs covered with the PDDA and the $\left[\mathrm{P}_{2} \mathrm{~W}_{17} \mathrm{VO}_{62}\right]^{8-}$ over-layer. The results pointed out that diameters of CNTs did not increase significantly following their modifications. This observation is consistent with the view that we are dealing with ultra-thin layers of both PDDA and $\left[\mathrm{P}_{2} \mathrm{~W}_{17} \mathrm{VO}_{62}\right]^{8-}$ (the latter being likely on the monolayer level) on the surfaces of CNTs. It cannot also be excluded that deposition proceeded predominantly at defective sites of side walls as well as at the ends of CNTs as previously postulated [21, 51].

Electrochemical identity of composite films

Figure 2 a shows a cyclic voltammetric response of the CNTs/PDDA/ $\left[\mathrm{P}_{2} \mathrm{~W}_{17} \mathrm{VO}_{62}\right]^{8-}$ film (on glassy carbon) recorded in $0.5 \mathrm{~mol} \mathrm{dm}^{-3} \mathrm{H}_{2} \mathrm{SO}_{4}$. Four sets of fairly welldefined voltammetric peaks were observed, and they could be correlated with four separate redox transitions 
Fig. 1 TEM images of CNTs a before and after modification with $\mathbf{b}$ PDDA monolayer and $\mathbf{c}$ $\mathrm{PDDA} /\left[\mathrm{P}_{2} \mathrm{~W}_{17} \mathrm{VO}_{62}\right]^{8-}$ bilayer
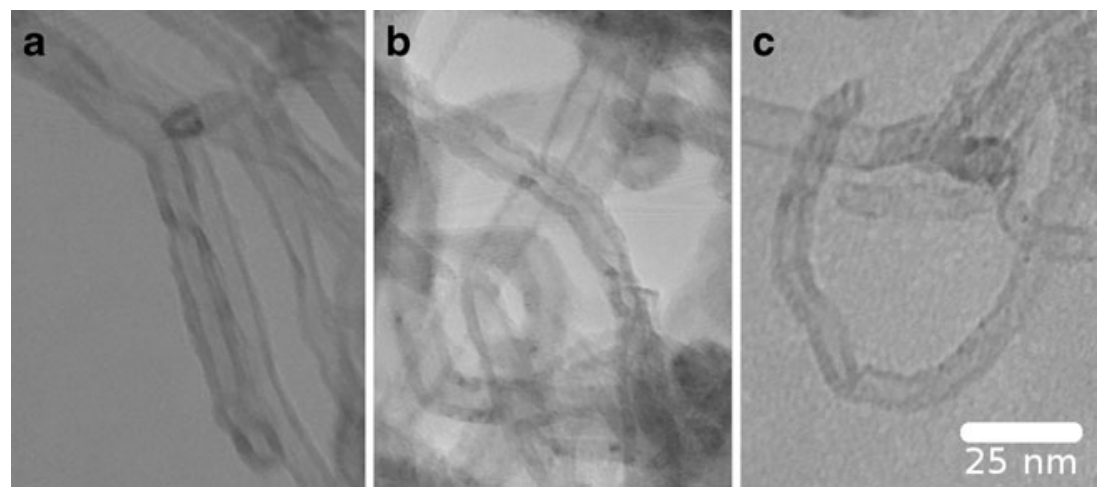

characterized by the following formal potentials $\left(E_{\mathrm{c}}{ }^{\ominus \prime}\right)$ equal to $0.376,0.000,-0.188$, and $-0.392 \mathrm{~V}$. Here the $E_{\mathrm{c}}^{\ominus}$, values were calculated as an average of the reduction and oxidation peaks potentials $\left(\left(E_{\text {peak }}^{\text {red }}+E_{\text {peak }}{ }^{\text {ox }}\right) / 2\right)$. First set of peaks, i.e., appearing at the most positive potentials and labeled as 1 , should be attributed to the $\mathrm{V}^{\mathrm{IV} / \mathrm{V}}$ redox process. The origin of the second redox process, labeled as 2 , is not clear. Perhaps, this reaction could be ascribed to the redox activity of oxygen-surface groups in CNTs or to the presence and electroactivity of different vanadium forms (less likely). The last two reversible reduction waves, marked as 3 and 4, should correspond to bi-electronic redox processes of oxotungstate units according to the reaction [52]:

$\mathrm{P}_{2} \mathrm{~W}_{17}{ }^{\mathrm{VI}} \mathrm{VO}_{62}{ }^{8-}+\mathrm{ne}^{-}+\mathrm{nH}^{+} \rightleftarrows \mathrm{H}_{\mathrm{n}} \mathrm{P}_{2} \mathrm{~W}_{\mathrm{n}}{ }^{\mathrm{V}} \mathrm{W}_{17-\mathrm{n}}{ }^{\mathrm{VI}} \mathrm{VO}_{62}{ }^{8-}$

where $n$ is equal to 2 and 4 , respectively. For comparison, Fig. 2 b, c shows electrochemical behavior of (b) bare CNTs and (c) $\left[\mathrm{P}_{2} \mathrm{~W}_{17} \mathrm{VO}_{62}\right]^{8-}\left(1 \mathrm{mmol} \mathrm{dm}{ }^{-3}\right.$ solution) during voltammetric cycling in $0.5 \mathrm{~mol} \mathrm{dm}{ }^{-3} \mathrm{H}_{2} \mathrm{SO}_{4}$. It can be observed that in the case of $\left[\mathrm{P}_{2} \mathrm{~W}_{17} \mathrm{VO}_{62}\right]^{8-}$ dissolved in solution, a fifth well-defined reversible reduction process was also detected at potentials more negative than $-0.5 \mathrm{~V}$. This electrode reaction should be attributed to the third bi-electronic oxotungstate redox process $(n=6)$. However, studies of our composite film showed that the $\mathrm{CNTs} / \mathrm{PDDA} /\left[\mathrm{P}_{2} \mathrm{~W}_{17} \mathrm{VO}_{62}\right]^{8-}$ composite stability was higher up to $20 \%$ when the system was subjected to the long-term $(4 \mathrm{~h})$ voltammetric potential cycling within the potential range restricted to the first two oxotungstate redox processes (i.e., down to $-0.5 \mathrm{~V}$ ). In addition, it was previously reported that potential cycling over the three oxotungstate processes could destabilize the polyoxometalate structure [50]. As a result, our electrochemical study was confined to the $\mathrm{V}^{\mathrm{IV} / \mathrm{V}}$ and the first two oxo-tungstate redox processes.

It is noteworthy that $E_{\mathrm{c}}{ }^{\ominus,}$ values found for $\left[\mathrm{P}_{2} \mathrm{~W}_{17} \mathrm{VO}_{62}\right]^{8-}$ existing in the composite $\mathrm{CNTs} / \mathrm{PDDA}$ material were fairly close to those obtained for the $\left[\mathrm{P}_{2} \mathrm{~W}_{17} \mathrm{VO}_{62}\right]^{8-}$ dissolved in solution $\left(E_{\mathrm{c}}{ }^{\prime} 0.43,-0.17,-0.38\right.$, and $\left.-0.65 \mathrm{~V}\right)$. This phenomenon may suggest that physicochemical of heteropolyanion is retained following adsorption, as well as there is no significant difference between adsorption strength of heteropolytungstate oxidized and reduced form. Therefore, our system behaved in an analogous manner to the other POMs, such as $\mathrm{SiW}_{12}, \mathrm{PMo}_{12}$, and $\mathrm{P}_{2} \mathrm{Mo}_{18}$, that were found to be well-maintained and electroactive within the CNTs nanocomposites [47].

All redox processes illustrated in Fig. 2 a exhibited the peak-to-peak $\left(\Delta E_{\text {peak }}\right)$ separations of less than $20 \mathrm{mV}$, except the unidentified process marked as 2 for which $\Delta E_{\text {peak }}$ $=30 \mathrm{mV}$. On the whole, it could be concluded that we were dealing with the surface confined species characterized by fast and reversible redox transitions. The full widths at half maximum values (FWHM) obtained from Fig. 2 a for the $\mathrm{CNTs} / \mathrm{PDDA} /\left[\mathrm{P}_{2} \mathrm{~W}_{17} \mathrm{VO}_{62}\right]^{8-}$ composite were found to be $138,102,66$, and $58 \mathrm{mV}$ for the respective oxidation waves of the redox processes labeled as 1,2,3, and 4 . The first two values were larger than the theoretically predicted value of

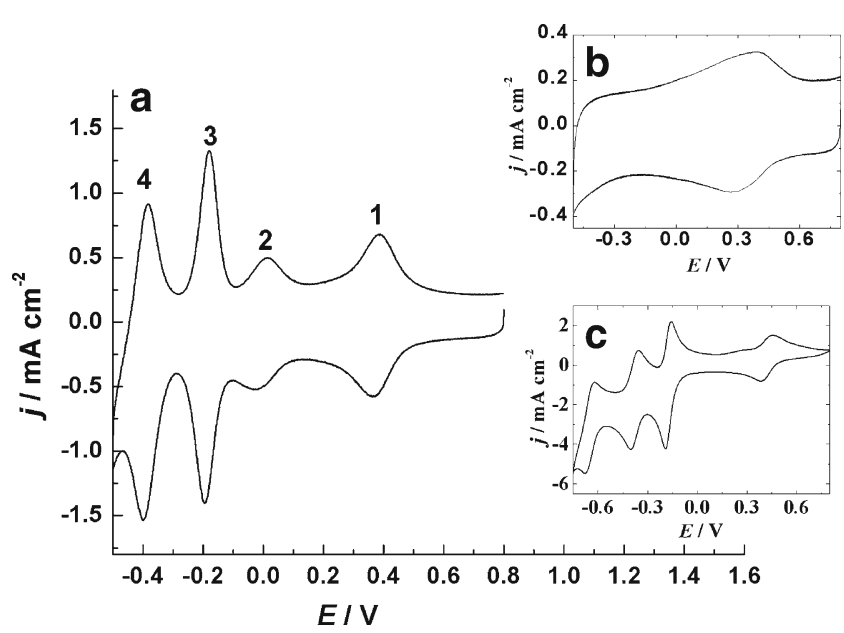

Fig. $2 \mathrm{CNTs} / \mathrm{PDDA} /\left[\mathrm{P}_{2} \mathrm{~W}_{17} \mathrm{VO}_{62}\right]^{8-}$ composite electrode cycled $\left(10 \mathrm{mV} \mathrm{s}^{-1}\right)$ in $a$ aqueous solution of $0.5 \mathrm{~mol} \mathrm{dm}^{-3} \mathrm{H}_{2} \mathrm{SO}_{4}$. Insets $b$ and $c$ show cyclic voltammetric response of bare CNTs and dissolved $\left[\mathrm{P}_{2} \mathrm{~W}_{17} \mathrm{VO}_{62}\right]^{8-}\left(1 \mathrm{~mol} \mathrm{dm}{ }^{-3}\right)$, respectively, recorded in $0.5 \mathrm{~mol} \mathrm{dm}^{-3}$ $\mathrm{H}_{2} \mathrm{SO}_{4}$. Working electrode: glassy carbon electrode $\left(A=0.071 \mathrm{~cm}^{2}\right)$. CNT-based electrode material loading, $0.4 \mathrm{mg} \mathrm{cm}^{-2}$ 
$90.6 \mathrm{mV}$ for the ideal monoelectronic surface transfer reaction [53]. The last two values also exceeded the anticipated $45.3 \mathrm{mV}$ expected for bi-electronic redox process. It is believed that appearance of FWHM values higher than those theoretically predicted typically reflects repulsive interactions within the film [54]. Moreover, the above results could also be explained by the peak broadening due to the existence of high background currents originating from the double-layer capacitive currents as well as electroactivity of surface groups of CNTs [19] as it is apparent from inset b of Fig. 2 illustrating a cyclic voltammetric response of bare CNTs in $0.5 \mathrm{~mol} \mathrm{dm}^{-3} \mathrm{H}_{2} \mathrm{SO}_{4}$. CNTs were attached to the glassy carbon substrate as described in "Experimental" section, except that the their layer was not subjected to further modification.

Some attention has to be paid to the appearance of voltammetric responses in the range from 0.2 to $0.4 \mathrm{~V}$ [16]. As previously mentioned [55], "bamboo-shaped" multi-walled CNTs exhibited (in $1 \mathrm{~mol} \mathrm{dm}^{-3} \mathrm{H}_{2} \mathrm{SO}_{4}$ ) the anodic peak at about $0.45 \mathrm{~V}$ and the cathodic one at $0.40 \mathrm{~V}$ originating from the oxidation and reduction of surface quinoidal functional groups. A high electrode capacitance, as evident from the large separation baselines between the anodic and cathodic scans in cyclic voltammograms of CNTs, was also postulated [56]. In the case of acid treated single-walled carbon nanotubes, contributions from the charging of electrical double layer and from the pseudocapacitance effects related to surface Faradaic (redox) reactions were found sizeable [57]. Therefore, it is reasonable to assume that the peak broadening observed here for bare multi-walled CNTs (inset b of Fig. 2) was due to the electroactivity of surface electroactive groups of CNTs and to the presence of high capacitive currents in this range of potential.

The CNTs/PDDA/ $\left[\mathrm{P}_{2} \mathrm{~W}_{17} \mathrm{VO}_{62}\right]^{8-}$ modified electrode was also studied in the electrolytes of various pH's. Figure 3 a illustrates cyclic voltammogram recorded in aqueous solution of $\mathrm{pH} 7.0$ as the representative one. The $\left[\mathrm{P}_{2} \mathrm{~W}_{17} \mathrm{VO}_{62}\right]^{8-}$ polyanion was found electroactive in the wide range of $\mathrm{pH}$ 's varying from 0 to 7 . Nevertheless, the higher the $\mathrm{pH}$ values, the more poorly developed peaks of lower current densities were recorded. The results showed that, with increasing $\mathrm{pHs}$, the two bi-electronic oxotungstate redox peaks, labeled as 3 and 4, shifted to lower values of potentials (linear relationship for the representative set of peaks labeled as 3 is shown in inset b of Fig. 3). The positions of redox couples labeled as 1 and 2 were almost $\mathrm{pH}$-independent. The slope values of the $E_{\mathrm{c}}{ }^{\prime}$ vs. $\mathrm{pH}$ plots for the oxotungstate-based redox processes labeled as 3 and as 4 were found to be 70 and $69 \mathrm{mV}$ per $\mathrm{pH}$ unit. The results corresponded to the addition of two protons as was observed with the solution phase species of the other Dawson-type POMs [50].

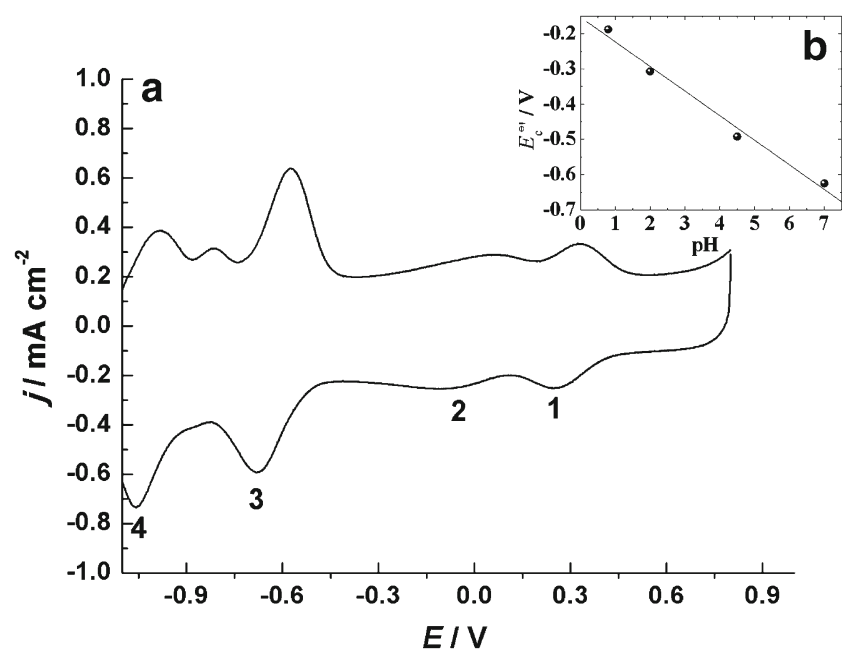

Fig. $3 \mathrm{CNTs} / \mathrm{PDDA} /\left[\mathrm{P}_{2} \mathrm{~W}_{17} \mathrm{VO}_{62}\right]^{8-}$ composite electrode cycled $\left(10 \mathrm{mV} \mathrm{s}^{-1}\right)$ in $a$ aqueous solution of $\mathrm{pH} 7\left(0.1 \mathrm{~mol} \mathrm{dm}{ }^{-3} \mathrm{Na}_{2} \mathrm{SO}_{4}+\right.$ $\left.0.02 \mathrm{~mol} \mathrm{dm}^{-3} \mathrm{NaH}_{2} \mathrm{PO}_{4}\right)$. Inset $b$ shows plot of $E^{\text {plimsoll }}$ vs $\mathrm{pH}$ for $\mathrm{CNTs} / \mathrm{PDDA} /\left[\mathrm{P}_{2} \mathrm{~W}_{17} \mathrm{VO}_{62}\right]^{8-}$ composite for process labeled 3. Working electrode: glassy electrode $\left(A=0.071 \mathrm{~cm}^{2}\right)$. CNT-based electrode material, $0.4 \mathrm{mg} \mathrm{cm}^{-2}$

A scan rate study performed in $0.5 \mathrm{~mol} \mathrm{dm}{ }^{-3} \mathrm{H}_{2} \mathrm{SO}_{4}$ using the $\mathrm{CNTs} / \mathrm{PDDA} /\left[\mathrm{P}_{2} \mathrm{~W}_{17} \mathrm{VO}_{62}\right]^{8-}$ system (CNT-based electrode material loading, $0.4 \mathrm{mg} \mathrm{cm}^{-2}$ ) showed that the peak potentials associated with all the observed redox processes were independent of scan rate (Fig. 4 a), as well as that the peak current densities were directly proportional to scan rates of up to $1 \mathrm{~V} \mathrm{~s}^{-1}$ (inset $\mathrm{b}$ of Fig. 4). The data indicated existence of the surface controlled redox processes. In addition, some work on the effect of the composite thickness was carried out. In the case of thicker electrode, where the CNT-based material loading was $1 \mathrm{mg} \mathrm{cm}^{-2}$, it was found that for the plot of current density versus scan

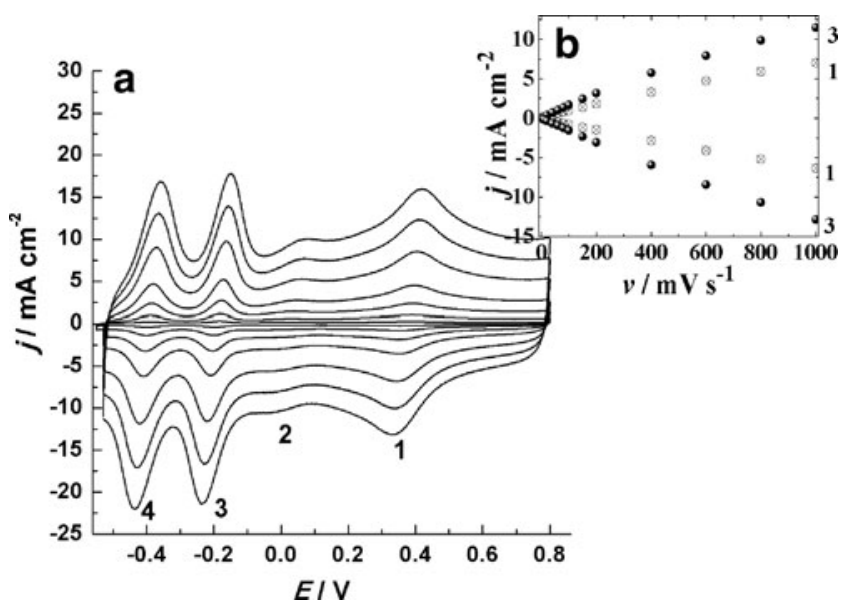

Fig. $4 \mathrm{CNTs} / \mathrm{PDDA} /\left[\mathrm{P}_{2} \mathrm{~W}_{17} \mathrm{VO}_{62}\right]^{8-}$ composite electrode cycled in $0.5 \mathrm{~mol} \mathrm{dm}^{-3} \mathrm{H}_{2} \mathrm{SO}_{4}$ at scan rates: 40 (inner line), 100, 200, 400, $600,800 \mathrm{mV} \mathrm{s}^{-1}$ (outer line). Inset shows the dependence of the oxidation and reduction peak current density on scan rate for processes labeled 1 and 3. Working electrode: glassy carbon electrode ( $A=$ $0.071 \mathrm{~cm}^{2}$ ). CNT-based electrode material loading, $0.4 \mathrm{mg} \mathrm{cm}$ 
rate, linearity existed only up to $0.1 \mathrm{~V} \mathrm{~s}^{-1}$ most likely because of charge transfer and diffusion limitations. At scan rates beyond this range, an increase in the peak splitting was observed, eventually leading to a loss of peak symmetry (for simplicity data not shown here).

The stability of the CNTs/PDDA/[ $\left.\mathrm{P}_{2} \mathrm{~W}_{17} \mathrm{VO}_{62}\right]^{8-}$ composite, where CNT-based material loading was $0.4 \mathrm{mg} \mathrm{cm}^{-2}$, was investigated by subjecting the system to the long-term voltammetric potential cycling in $0.5 \mathrm{~mol} \mathrm{dm}^{-3} \mathrm{H}_{2} \mathrm{SO}_{4}$ electrolyte. The composite was found to be fairly stable within the potential range from 0.8 to $-0.55 \mathrm{~V}$; indeed, the loss of activity lower than $15 \%$ was observed with respect to all the observed redox processes following 100 cycles at $50 \mathrm{mV} \mathrm{s}^{-1}$. We found that the investigated system exhibited lower stability in more alkaline media: The percentage losses of activities were up to 30 and $20 \%$ at $\mathrm{pH} 4.5$ and 7.0 , respectively. This could be linked to the $\mathrm{pH}$-dependent nature of the polytungstate reduction processes: In alkaline media, availability of protons which are needed to accompany the reductions is obviously lower relative to that in $0.5 \mathrm{~mol} \mathrm{dm}^{-3} \mathrm{H}_{2} \mathrm{SO}_{4}$ [2].

It was found that an addition of diethyl ether to the ink suspension caused an increase (approximately by $50 \%$ ) of the current densities associated with all the observed redox processes of the CNTs/PDDA/ $\left[\mathrm{P}_{2} \mathrm{~W}_{17} \mathrm{VO}_{62}\right]^{8-}$ composite. This phenomenon could be explained in terms of the enhanced attachment of PDDA and, later, $\left[\mathrm{P}_{2} \mathrm{~W}_{17} \mathrm{VO}_{62}\right]^{8-}$. This could be ascribed to the formation of the CNT surface groups enhanced or activated by diethyl ether. Our recent studies also showed that an increase of the current intensities was also seen when the ink suspension was prepared using CNTs that had already been modified with PDDA and $\left[\mathrm{P}_{2} \mathrm{~W}_{17} \mathrm{VO}_{62}\right]^{8-}$. It is reasonable to expect that current increases were caused by so-called current doubling historically observed in the presence of different organic molecules $[58,59]$. As the observed effect led to the pseudocapacitance increase, the ink suspension was prepared as a rule with addition of diethyl ether.

\section{Dynamics of charge transport}

An effective (apparent) diffusion coefficient $D_{\text {eff }}$ was previously estimated for charge transport of different systems [60]. However, in the case of our composite system, there was some uncertainty with respect to the estimation of the polytungstate redox centers concentration $\left(C_{0}\right)$, namely due to the high specific surface area of CNTs. This could be responsible for an error in the determination of $D_{\text {eff. }}$ Therefore, a series of chronocoulometric (potential step) experiments was performed to estimate a kinetic parameter $D_{\text {eff }}^{1 / 2} C_{0}$ (rather than simply $\left.D_{\text {eff }}\right)$ for the $\mathrm{CNTs} / \mathrm{PDDA} /\left[\mathrm{P}_{2} \mathrm{~W}_{17} \mathrm{VO}_{62}\right]^{8-}$ composite. The parameter was determined by usual means [60], i.e., from the slopes of dependencies of charge $(Q)$ versus square root of time $\left(t^{1 / 2}\right)$ and using integrated Cottrell equation. Figure 5 illustrates the chronocoulometric potential step response recorded in $0.5 \mathrm{~mol} \mathrm{dm}^{-3} \mathrm{H}_{2} \mathrm{SO}_{4}$ for the $\mathrm{CNTs} / \mathrm{PDDA} /\left[\mathrm{P}_{2} \mathrm{~W}_{17} \mathrm{VO}_{62}\right]^{8-}$ composite system deposited on glassy carbon (CNT-based material loading, $0.4 \mathrm{mg} \mathrm{cm}^{-2}$ ). The calculated kinetic parameter was equal $8.4 \times 10^{-8} \mathrm{~mol} \mathrm{~cm}^{-2} \mathrm{~s}^{-1 / 2}$. It is known that typical $D_{\text {eff }}$ values for redox conducting films (on electrodes) containing redox centers at concentration of $0.2-1.5 \mathrm{mmol} \mathrm{cm}^{-3}$ lie in the range $1 \times 10^{-10}-4 \times 10^{-7} \mathrm{~cm}^{2} \mathrm{~s}^{-1}$ [60]. The result translates to the $D_{\text {eff }}{ }^{1 / 2} C_{0}$ values ranging from $2 \times 10^{-9}$ to $1 \times$ $10^{-6} \mathrm{~mol} \mathrm{~cm}^{-2} \mathrm{~s}^{-1 / 2}$. Thus, our kinetic parameter was consistent with the moderately fast dynamics of charge propagation within the $\mathrm{CNTs} / \mathrm{PDDA} /\left[\mathrm{P}_{2} \mathrm{~W}_{17} \mathrm{VO}_{62}\right]^{8-}$ composite. Similar results were obtained for different loadings of CNT-based materials $\left(0.2-1 \mathrm{mg} \mathrm{cm}^{-2}\right)$.

\section{Charging/discharging characteristics}

Figure 6 shows galvanostatic charging-discharging curves recorded under constant current of $200 \mathrm{~mA} \mathrm{~g}^{-1}$ for bare CNTs and CNTs/PDDA/[ $\left.\mathrm{P}_{2} \mathrm{~W}_{17} \mathrm{VO}_{62}\right]^{8-}$ composite. The charging and discharging times were by approximately $36 \%$ longer for the latter system with the CNT-based electrode material loading of $0.4 \mathrm{mg} \mathrm{cm}^{-2}$ (Fig. $6 \mathrm{a}, \mathrm{b}$ ).

Using the data from discharging segments of Fig. 6, the specific capacitance, $C$, values (per gram of carbon nanotubes material) were estimated in similar manner as described previously [16], namely by using of the following equation: $C=\frac{i \cdot t}{\Delta E \cdot m}$ (where $t$-discharge time, $i$-discharge current, $\Delta E$-potential difference, $m$-mass of the electrode material). The following $C$ values were obtained: 50 and $82 \mathrm{~F} \mathrm{~g}^{-1}$ at the current of $200 \mathrm{~mA} \mathrm{~g}^{-1}$ for the bare CNTs and



Fig. 5 Double potential step chronocoulometric plot for CNTs/PDDA/ $\left[\mathrm{P}_{2} \mathrm{~W}_{17} \mathrm{VO}_{62}\right]^{8-}$ composite deposited on GC plate $\left(A=1 \mathrm{~cm}^{2}\right)$. An initial potential step was from 0.7 to $-0.5 \mathrm{~V}$ vs SCE. Pulse width, $2 \mathrm{~s}$. Electrolyte, $0.5 \mathrm{~mol} \mathrm{dm}^{-3} \mathrm{H}_{2} \mathrm{SO}_{4}$. CNT-based electrode material loading, $0.4 \mathrm{mg} \mathrm{cm}^{-2}$ 




Fig. 6 Galvanostatic charging-discharging curves recorded for $a$ bare CNTs and $b$ CNTs/PDDA/ $\left[\mathrm{P}_{2} \mathrm{~W}_{17} \mathrm{VO}_{62}\right]^{8-}$ composite electrode. Current load, $200 \mathrm{~mA} \mathrm{~g}^{-1}$. Electrolyte, $0.5 \mathrm{~mol} \mathrm{dm}^{-3} \mathrm{H}_{2} \mathrm{SO}_{4}$. Working electrode: glassy carbon plate $\left(A=1 \mathrm{~cm}^{2}\right)$. CNT-based electrode material loading, $0.4 \mathrm{mg} \mathrm{cm}^{-2}$

the $\mathrm{CNTs} / \mathrm{PDDA} /\left[\mathrm{P}_{2} \mathrm{~W}_{17} \mathrm{VO}_{62}\right]^{8-}$ composite, respectively (the CNT-based material loading of $0.4 \mathrm{mg} \mathrm{cm}^{-2}$ was applied in both cases). These values corresponded to 0.3 (for bare) and $0.5 \mathrm{~F} \mathrm{~cm}^{-2}$ (for modified) carbon material. This suggested a relatively high contribution of pseudocapacitance to the overall capacitance due to the presence of the $\left[\mathrm{P}_{2} \mathrm{~W}_{17} \mathrm{VO}_{62}\right]^{8-}$, although only a thin POM layer was present. In addition, the value of $C$ for the $C N T s / P D D A /\left[\mathrm{P}_{2} \mathrm{~W}_{17} \mathrm{VO}_{62}\right]^{8-}$ was reasonably high in comparison to those reported in the literature for the other POM-based hybrid materials. Similar specific capacitance values up to $0.6 \mathrm{~F} \mathrm{~cm}^{-2}$ were determined from voltammetric measurements (at scan rate of $5 \mathrm{mV} \mathrm{s}^{-1}$ ) for the hybrid material made of onion-like-carbons chemically modified with Keggin-type POM together with PDDA. The result was $20 \%$ higher than the one observed for bare carbon onions [46]. On the other hand, a very high specific capacitance of $168 \mathrm{~F} \mathrm{~g}^{-1}$ was obtained under constant current of $400 \mathrm{~mA} \mathrm{~g}^{-1}$ for the hybrid material based on polyaniline and Keggin-type POM [15]. However, it should be mentioned here that the conducting polymer matrix had much larger contribution to the overall capacitance that pure double-layer carbon material. For example, CNTs modified with POM adsorbates (monolayers) yielded much lower capacitance, namely $40 \mathrm{~F} \mathrm{~g}^{-1}$ at the current of $200 \mathrm{~mA} \mathrm{~g}^{-1}$ [16]. To conclude, the results obtained by different authors rather should not be compared directly because usually different approaches are used for material preparation and electrochemical testing. Nevertheless, this report confirms again the pseudocapacitance nature of POMs.

Upon application of increasing currents, ranging from 200 to $5000 \mathrm{~mA} \mathrm{~g}^{-1}$, the specific capacitance (estimated by galvanostatic method) of our two investigated systems decreased (Fig. 7). Following an initial rapid decrease, a leveling effect was observed at currents exceeding $3 \mathrm{~A} \mathrm{~g}^{-1}$ and specific capacitance started to oscillate around the value of $40 \mathrm{~F} \mathrm{~g}^{-1}$ in the case of CNTs/PDDA/[ $\left.\mathrm{P}_{2} \mathrm{~W}_{17} \mathrm{VO}_{62}\right]^{8-}$ and around $20 \mathrm{~F} \mathrm{~g}^{-1}$ in the case of bare CNTs. This type of behavior was expected as it is known that with increasing currents, capacitances decrease due to the shortened charging/ discharging times $[14,16]$. Although an initial rapid current decrease might imply some limitations of charge propagation, it could be assumed that electrode materials considered here exhibited fast charge propagation dynamics as under high current condition (above $3 \mathrm{~A} \mathrm{~g}^{-1}$ ), no rapid decrease of capacitance was observed. This was consistent with the results of chronocoulometric (potential step) experiments.

In order to verify the obtained specific capacitance values for the $\mathrm{CNTs} / \mathrm{PDDA} /\left[\mathrm{P}_{2} \mathrm{~W}_{17} \mathrm{VO}_{62}\right]^{8-}$ composite, they were also estimated by cyclic voltammetry and impedance spectroscopy. These techniques were chosen because both of them were previously used to estimate capacitance. Particularly, impedance spectroscopy was earlier reported to be a useful technique for the measurements of capacitance giving complementary results $[16,41]$.

The specific capacitance values determined from cyclic voltammetry were estimated using generally accepted equation [16]: $C=\frac{i_{\mathrm{c}}}{v \cdot m}$, where $i_{\mathrm{c}}$ is capacitance current, $v$ is scan rate, and $m$ is mass of the electrode active material (Fig. 8 a). The impedance spectroscopy results were collected in the frequency range of $20 \mathrm{mHz}-100 \mathrm{kHz}$ with the amplitude of $5 \mathrm{mV}$. Seven different potential values were applied to the modified electrodes, namely $0.6,0.48,0.2,0.4,0.0,-0.2$, and $-0.4 \mathrm{~V}$ vs SCE. Using these data, the specific capacitances were estimated in similar manner as described previously for

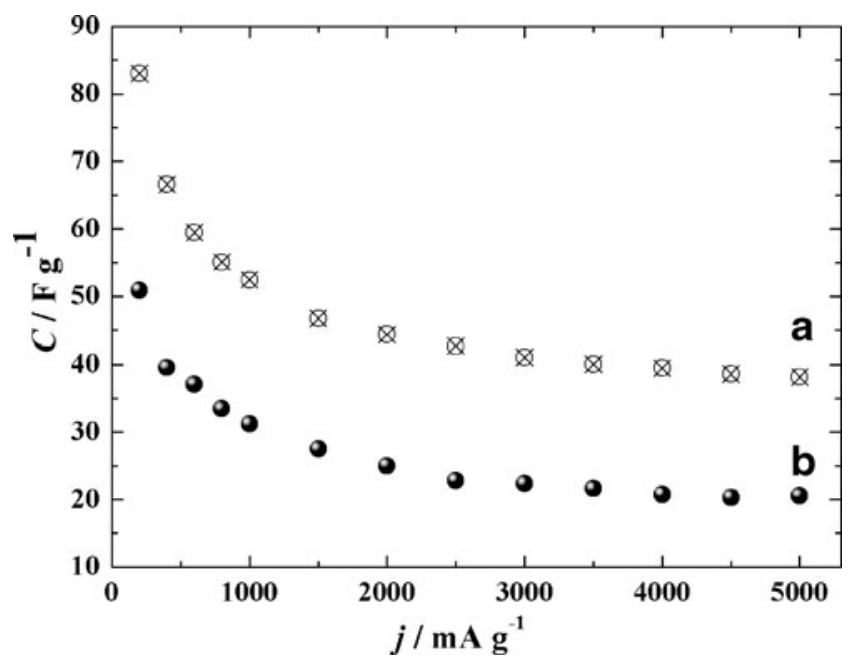

Fig. 7 Dependences of specific capacitances on increasing discharging currents for: $a$ bare CNTs and $b$ CNTs/PDDA/ $\left[\mathrm{P}_{2} \mathrm{~W}_{17} \mathrm{VO}_{62}\right]^{8-}$ composite. Working electrode: glassy carbon plate $\left(A=1 \mathrm{~cm}^{2}\right)$. CNT-based electrode material loading, $0.4 \mathrm{mg} \mathrm{cm}^{-2}$ 
double layer capacitance [61]. Inset b in Fig. 8 shows Nyquist $\mathrm{AC}$ impedance plots for the $\mathrm{CNTs} / \mathrm{PDDA} /\left[\mathrm{P}_{2} \mathrm{~W}_{17} \mathrm{VO}_{62}\right]^{8-}$ composite recorded when potential of $-0.4 \mathrm{~V}$ vs SCE was applied. Examination of Nyquist impedance plots (inset $b$ in Fig. 8) could suggest porous nature of the investigated material [61]; however, it was difficult to approximate the Nyquist impedance plots (Fig. 8) for the CNTs/PDDA/[ $\left[\mathrm{P}_{2} \mathrm{~W}_{17} \mathrm{VO}_{62}\right]^{8-}$ composites using the porous electrode model. Nevertheless, it was possible to approximate experimental data using the model presented in Fig. 8.

As seen in Fig. 8 a, the average $C$ values determined from the cyclic voltammetry and impedance spectroscopy data were comparable to those estimated by galvanostatic method. Some inconsistencies could be explained by differences in the approaches to capacitance estimation [16]. It is also noteworthy that no kinetic semicircles were observed. However, this could be attributed to the fast reaction kinetics [61]. Despite the fact that vanadium heteropolytungstate redox transitions (involving electron transfers between $\left.\mathrm{W}^{(\mathrm{V})}, \mathrm{W}^{(\mathrm{VI})}\right)$ appear in the negative range of potentials, the electrolyte decomposition has not been observed. It indicates that PDDA/ $\left[\mathrm{P}_{2} \mathrm{~W}_{17} \mathrm{VO}_{62}\right]^{8-}$ suppresses the hydrogen evolution what makes the composite material a good candidate for negative electrode in asymmetric supercapacitors operating in the electrolytes of various $\mathrm{pH}$ 's.

\section{Electrocatalytic activity toward bromate reduction}

We also considered electrocatalytic properties of the $\mathrm{CNTs} / \mathrm{PDDA} /\left[\mathrm{P}_{2} \mathrm{~W}_{17} \mathrm{VO}_{62}\right]^{8-}$ hybrid material. Two model

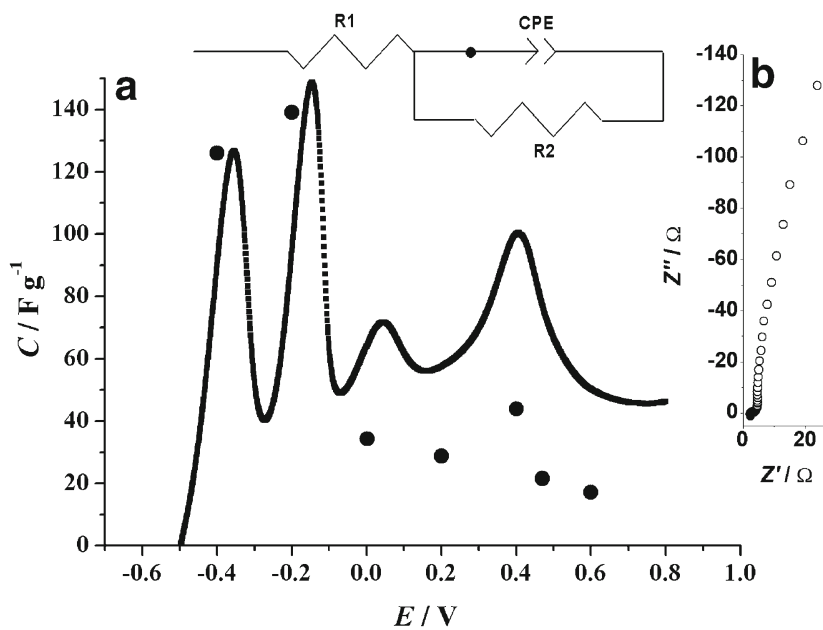

Fig. 8 a Specific capacitance values determined by square cyclic voltammetry $\left(10 \mathrm{mV} \mathrm{s}^{-1}\right)$ and circle impedance spectroscopy for $\mathrm{CNTs} / \mathrm{PDDA} /\left[\mathrm{P}_{2} \mathrm{~W}_{17} \mathrm{VO}_{62}\right]^{8-}$ composite. Inset $b$ shows Nyquist impedance plots of imaginary component $\left(Z^{\prime \prime}\right)$ on real component $\left(Z^{\prime}\right)$. Considering frequency range, $20 \mathrm{mHz}-100 \mathrm{kHz}$; amplitude, $5 \mathrm{mV}$; applied potential, $-0.4 \mathrm{~V}$. Working electrode: glassy carbon plate $(A=$ $1 \mathrm{~cm}^{2}$ ). CNT-based electrode material loading, $0.4 \mathrm{mg} \mathrm{cm}^{-2}$. Equivalent circuit included is consisted of: $R 1$ electrolyte resistance, $R 2$ charge transfer resistance, $C P E$ constant phase element inorganic reactants were taken into account, namely bromate and nitrite. Fairly small cathodic currents were recorded following exposure of the glassy carbon electrode modified with the $\mathrm{CNTs} / \mathrm{PDDA} /\left[\mathrm{P}_{2} \mathrm{~W}_{17} \mathrm{VO}_{62}\right]^{8-}$ to $3 \mathrm{mmol} \mathrm{dm}{ }^{-3} \mathrm{NO}_{2}{ }^{-}$solution (for simplicity data not shown here). However, the catalytic film exhibited a sizeable activity at the potential of $0.75 \mathrm{~V}$ that should be attributed to the nitrite oxidation, a process mainly catalyzed by CNTs as reported earlier [62]. The electrocatalytic responses were also obtained in the solution containing bromate anions. The respective cyclic voltammetric curves were recorded in $0.5 \mathrm{~mol} \mathrm{dm}^{-3} \mathrm{H}_{2} \mathrm{SO}_{4}$ containing 0,3 , and $7 \mathrm{mmol} \mathrm{dm}^{-3} \mathrm{KBrO}_{3}$ (Fig. 9 a). Electrocatalytic responses were already visible in $0.1 \mathrm{mmol} \mathrm{dm}^{-3}$ solution of bromate. The reduction process started readily at about $0.1 \mathrm{~V}$, where quinoidal groups existing at CNTs may
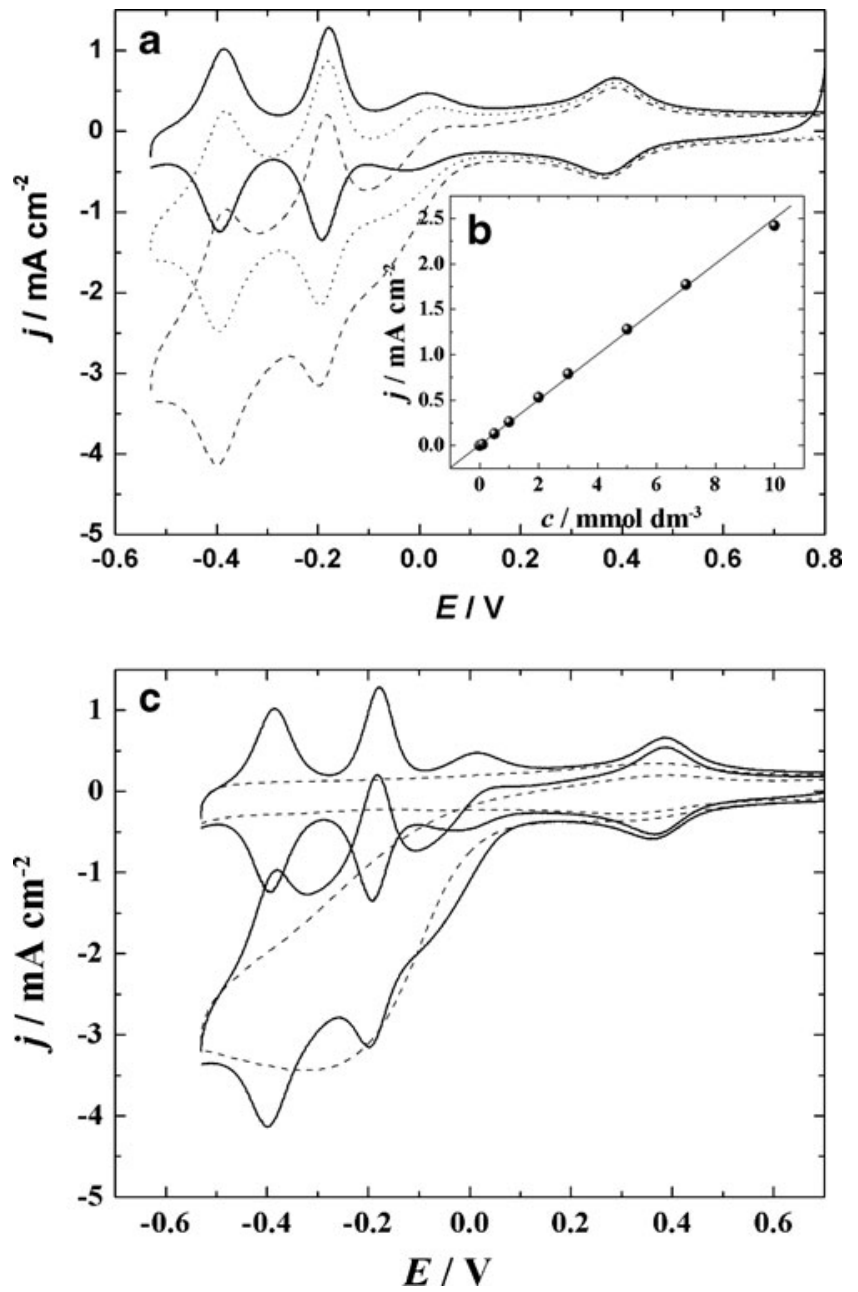

Fig. $9 a$ Cyclic voltammetric curves for CNTs/PDDA/[ $\left.\mathrm{P}_{2} \mathrm{~W}_{17} \mathrm{VO}_{62}\right]^{8-}$ composite electrode recorded in $0.5 \mathrm{~mol} \mathrm{dm}^{-3} \mathrm{H}_{2} \mathrm{SO}_{4}$ containing: 0 (solid line), 3 (dotted line), and 7 (dashed line) $\mathrm{mmol} \mathrm{dm}^{-3} \mathrm{KBrO}_{3}$. Scan rate, $10 \mathrm{mV} \mathrm{s}^{-1} ; b$ shows the dependence of electrocatalytic current on bromate concentration; $c$ comparison of electrocatalytic activities of the layers of CNTs (dashed line) and CNTs/PDDA/ $\left[\mathrm{P}_{2} \mathrm{~W}_{17} \mathrm{VO}_{62}\right]^{8-}$ (solid line). Scan rate, $10 \mathrm{mV} \mathrm{s}^{-1}$. Bromate concentration, $3 \mathrm{mmol} \mathrm{dm}^{-3}$ 
contribute to the overall activity, but the electrocatalytic current was maximized when mixed-valent $\mathrm{W}^{(\mathrm{V}, \mathrm{VI})}$ redox centers were generated within the polytungstate structure. The typical reduction mechanism described for various types of Keggin and Dawson polyoxometalates [9, 26, 33-37] involves partially reduced (mixed-valent heteropolyblue) oxotungstate, or oxomolybdate redox centers. Because of very weak adsorption of vanadium heteropolytungstate on bare electrode substrates, it was difficult to investigate to what extent the heteropolyanion itself contributes to the electrocatalytic process. For this reason, contrast experiments utilizing electrodes covered with bare CNTs and CNTs modified with PDDA together with $\left[\mathrm{P}_{2} \mathrm{~W}_{17} \mathrm{VO}_{62}\right]^{8-}$ have been performed (Fig. 9 c). The obtained results show clearly that the predominant electrocatalytic activity originates from carbon nanotubes during the electrocatalytic process.

Using the voltammetric data, a dependence of the electrocatalytic current on $\mathrm{BrO}_{3}{ }^{-}$concentration was plotted (Fig. 9 b). Results were corrected for background currents recorded in the absence of bromate. The sensitivity parameter, demonstrated as a slope of the plot (shown in inset b), was calculated to be $0.24 \mathrm{~mA} \mathrm{~cm}{ }^{-2} \mathrm{mmol}^{-1} \mathrm{dm}^{3}$ which is much higher or comparable to those previously reported $[33,63,64]$.

\section{Conclusions}

Electrochemical properties of the CNTs modified with PDDA and the Dawson-type $\left[\mathrm{P}_{2} \mathrm{~W}_{17} \mathrm{VO}_{62}\right]^{8-}$ heteropolyanion were investigated here with the emphasis on charge and discharge characteristics as well as on the system's electrocatalytic properties. This hybrid material was found to be stable toward long-term voltammetric potential cycling in $0.5 \mathrm{~mol} \mathrm{dm}^{-3}$ $\mathrm{H}_{2} \mathrm{SO}_{4}$. The system's stability was lower, but still reasonable, in more neutral media (up to $\mathrm{pH}$ 7). It is important to note that mixed addenda heteropolyanions are more negatively charged (better attraction to positively charged matrices such as PDDA) and more physicochemically stable (even in the less acidic media). On the whole, the CNTs/PDDA/ $\left[\mathrm{P}_{2} \mathrm{~W}_{17} \mathrm{VO}_{62}\right]^{8-}$ composite system was characterized by fast propagation of charge regardless of the film thickness.

Modification of CNTs with PDDA and $\left[\mathrm{P}_{2} \mathrm{~W}_{17} \mathrm{VO}_{62}\right]^{8-}$ polyanion resulted in the capacitance increase due to the combination of the double-layer type capacitance with the redox of faraday pseudocapacitance. With regards to the capacitance determination, a reasonably good correlation was found between three used electrochemical methods, namely galvanostatic chargingdischarging, cyclic voltammetry, and AC impedance spectroscopy. The obtained value of specific capacitance, $82 \mathrm{~F} \mathrm{~g}^{-1}$ (measured at the current of $200 \mathrm{~mA} \mathrm{~g}^{-1}$ ), was higher by about $40 \%$ than the analogous values $\left(50 \mathrm{~F} \mathrm{~g}^{-1}\right)$ obtained for bare CNTs under the same experimental conditions.
$\mathrm{CNTs} / \mathrm{PDDA} /\left[\mathrm{P}_{2} \mathrm{~W}_{17} \mathrm{VO}_{62}\right]^{8-}$ hybrid material exhibited a high electrocatalytic activity toward reduction of bromate in the broad concentration range. However, the detailed experiments showed a predominant contribution from carbon nanotubes to the overall process. It is not clear to what extent the presence of vanadium ions and/or internal asymmetry of mixed addenda heteropolytungstate structure affects the system's high electrocatalytic activity during reductions (bromate).

Acknowledgments We are grateful to Dr. Iwona A. Rutkowska for her technical assistance during TEM measurements. This research was supported by National Science Center, Poland under project no. N N507 322040 and the Foundation for Polish Science (FNP) under Chair (Mistrz) Program.

Open Access This article is distributed under the terms of the Creative Commons Attribution License which permits any use, distribution, and reproduction in any medium, provided the original author(s) and the source are credited.

\section{References}

1. Pope MT (1983) Heteropoly and isopoly oxometalates. Springer, Berlin

2. Fay N, Dempsey E, McCormac T (2005) J Electroanal Chem 574:359-366

3. Liu S, Xu L, Gao G, Xu B, Guo W (2009) Mat Chem Phys 116:88-93

4. Kushch LA, Emel'yanov VA, Golhen S, Cador O, Schaniel D, Woike T, Ouahab L, Yagubskii EB (2009) Inorg Chim Acta 362:2279-2282

5. Bonastre J, Garce's P, Huerta F, Quijada C, Andio'n LG, Cases F (2006) Corros Sci 48:1122-1136

6. Kasai Y, Yamanaka S (1993) Japanese Patent Chem Abstr 121:37207

7. Cuentas-Gallegos AK, Martınez-Rosales R, Baibarac M, GomezRomero P, Rincon ME (2007) Electrochem Commun 9:2088-2092

8. Zeng H, Newkome GR, Hill CL (2000) Angew Chem Int Ed 39:1771-1774

9. Keita B, Mbomekalle IM, Nadjo L, de Oliveira P, Ranjbari A, Contant R (2005) CR Chim 8:1057-1066

10. Smith DP, Pope MT (1973) Inorg Chem 12:331

11. Abbessi M, Contant R, Thouvenot R, Herve G (1991) Inorg Chem 30:1695-1702

12. Contant R, Abbessi M, Thouvenot R, Herve G (2004) Inorg Chem 43:3597-3604

13. Goral M, Jouini M, Perruchot C, Miecznikowski K, Rutkowska IA, Kulesza PJ (2011) Electrochim Acta 56:3605-3615

14. Gomez-Romero P, Chojak M, Cuentas-Gallegos K, Asensio JA, Kulesza PJ, Casan-Pastor N, Lira-Cantu M (2003) Electrochem Commun 5:149-153

15. Vaillant J, Lira-Cantu M, Cuentas-Gallegos K, Casan-Pastor N, Gomez-Romero P (2006) Prog Solid State Ch 34:147-159

16. Skunik M, Chojak M, Rutkowska IA, Kulesza PJ (2008) Electrochim Acta 53:3862-3869

17. Foster K, Bi L, McCormac T (2008) Electrochim Acta 54:868-875

18. Lewera A, Zukowska G, Miecznikowski K, Chojak M, Wieczorek W, Kulesza PJ (2005) Anal Chim Acta 536:275-281 
19. Ito T, Yashiro H, Yamase T (2006) Langmuir 22:2806-2810

20. Karnicka K, Chojak M, Miecznikowski K, Skunik M, Baranowska B, Kolary A, Piranska A, Palys B, Adamczyk L, Kulesza PJ (2005) Bioelectrochemistry 66:79-87

21. Kulesza PJ, Skunik M, Baranowska B, Miecznikowski K, Chojak M, Karnicka K, Frackowiak E, Beguin F, Kuhn A, Delville MH, Starobrzynska B, Ernst A (2006) Electrochim Acta 51:2373-2379

22. Ernst A, Zoladek S, Wiaderek K, Cox JA, Kolary-Zurowska A, Miecznikowski K, Kulesza PJ (2008) Electrochim Acta 53:39243931

23. Kulesza PJ, Chojak M, Miecznikowski K, Lewera A, Malik MA, Kuhn A (2002) Electrochem Commun 4:510-515

24. Ingresoll D, Kulesza PJ, Faulkner LR (1994) J Electrochem Soc 141:140-147

25. Kuhn A, Anson FC (1996) Langmuir 12:5481-5488

26. Salimi A, Korani A, Hallaj R, Khoshnavazi R, Hadadzadeh H (2009) Anal Chim Acta 635:63-70

27. Fay N, Dempsey E, Kennedy A, McCormac T (2003) J Electroanal Chem 556:63-74

28. Wlodarczyk R, Chojak M, Miecznikowski K, Kolary A, Kulesza PJ, Marassi R (2006) J Power Sources 159:802-809

29. Cheng L, Dong S (2000) J Electrochem Soc 147:606-612

30. Cheng L, Cox J (2001) Electrochem Commun 3:285-289

31. Oh SY, Yun YJ, Kim DY, Han SH (1999) Langmuir 15:4690-92

32. Song Y, Wang E, Kang Z, Lan Y, Tian C (2007) Mat Res Bull 42:1485-1491

33. Skunik M, Kulesza PJ (2009) Anal Chim Acta 631:153-160

34. Bi LH, Wang EB, Xu L, Huang RD (2000) Inorg Chim Acta 305:163-171

35. Keita B, Mialane P, Secheresse F, de Oliviera P, Nadjo L (2007) Electrochem Commun 9:164-172

36. Unoura K, Iwashita A, Itabashi E, Tanaka N (1984) Bull. Chem Soc Jpn 57:597-605

37. Geletti YV, Bailey AJ, Boring EA, Hill CL (2001) Chem Commun 16:1484-1485

38. Ruiz V, Suarez-Guevara J, Gomez-Romero P (2012) Electrochem Commun 24:35-38

39. White AM, Slade RCT (2003) Electrochim Acta 48:2583-2588

40. Suppes GM, Cameron CG, Freund MS (2010) J Electrochem Soc 157:A1030-A1034

41. Frackowiak E, Beguin F (2001) Carbon 39:937-950

42. Ye JS, Liu X, Cui HF, Zhang WD, Ye JS, Sheu FS, Lim TM (2005) Electrochem Commun 7:249-245
43. Frackowiak E, Delpeux S, Jurewicz K, Szostak K, CazorlaAmoros D, Beguin F (2002) Chem Phys Lett 361:35-41

44. Obreja VVN (2008) Physica E 40:2596-2606

45. Zynek M, Serantoni M, Beloshapkin S, Dempsey E, McCormac T (2007) Electroanalysis 19:681-689

46. Park S, Lian K, Gogotsi Y (2009) J Electrochem Soc 156:A921926

47. Song Y, Wang E, Kang Z, Lan Y, Tian C (2007) Mater Res Bull 42:1485-1491

48. Harmalker SP, Leparulo MA, Pope MT (1983) J Am Chem Soc 105:4286-4292

49. Keita B, Girard F, Nadjo L, Contant R, Canny J, Richet M (1999) J Electroanal Chem 478:76-82

50. McCormac T, Fabre B, Bidan G (1997) J Electroanal Chem 427:155-1959

51. Sadakane M, Steckhan E (1998) Chem Rev 98:219-238

52. Skunik M, Baranowska B, Fattakhova D, Miecznikowski K, Chojak M, Kuhn A, Kulesza PK (2006) J Solid State Electr 10:168-175

53. Murray RW (1982) In: Bard AJ (ed) Chemically modified electrodes in electroanalytical chemistry. Marcel Dekker, New York

54. Bard AJ, Faulkner LR (2001) Electrochemical methods. Wiley, New York

55. Shanmugam S, Gedanken A (2006) J Phys Chem B 110:20372044

56. Gooding JJ (2005) Electrochim Acta 50:3049-3060

57. Barisci JN, Wallace GG, Baughman RH (2000) Electrochim Acta 46:509-517

58. Solarska R, Santato C, Jorand-Sartoretti C, Ulmann M, Augustynski J (2005) J Appl Electrochem 35:715-721

59. Morrison SR, Freund T (1967) J Chem Phys 47:1543-1551

60. Kulesza PJ, Malik MA (1999) In: Wieckowski A (ed) Interfacial electrochemistry, Ch. 23 Solid-state voltammetry. Marcel Dekker, New York

61. Jurczakowski R, Hitz C, Lasia A (2004) J Electroanal Chem 572:355-366

62. Zheng D, Hu C, Peng Y, Hu S (2009) Electrochim Acta 54:4910 1415

63. Gu Y, Ma H, O'Halloran KP, Shi S, Zhang Z, Wang X (2009) Electrochim Acta 54:7194-7200

64. Li Y, Bu W, Wu L, Sun C (2005) Sensor Actuator B 107:921-928 